\title{
Memórias Sentimentais de João Miramar: metonímia de um Oswald de Andrade moderno
}

\begin{abstract}
Resumo:Este ensaio revisa o que estudiosos já disseram acerca da obra de Oswald de Andrade, em especial, de Memórias Sentimentais de João Miramar. O referido livro pode ser apontado como uma espécie de metonímia moderna oswaldiana, ou seja, como uma parte que expressa o espírito moderno desse escritor, configurando-se, assim, na ordem do mimético, como uma articulação entre o real e o imaginário através da ficção.
\end{abstract}

Palavras-chave: metonímia; mímesis; modernismo, Oswald de Andrade.

\begin{abstract}
This essay intends to perform a theoretical revision that emphasizes important studies about Oswald de Andrade's work, especially Memórias Sentimentais de João Miramar. This book can be pointed out as a kind of modern metonymy of Oswald de Andrade, in other words, as an expressive part of the modern spirit of this writer, being, therefore, in the order of mimesis, as an articulation between real and imaginary through fiction.
\end{abstract}

Keywords: metonymy; mimesis; modernism; Oswald de Andrade.

Personagem polêmica sob todos os aspectos (SCHWARTZ, 1983, p.153), talvez possamos dizer que Oswald de Andrade acabou tendo, pelo menos em parte, sua produção literária ofuscada pela sua ativa participação no cenário sócio-político do país. Candido chega a ressaltar a criação de um lendário e anedótico Oswald de Andrade que "escandalizava pelo fato de existir, porque a sua personalidade excepcionalmente poderosa atulhava o meio com a simples presença. Conheci muito senhor bem posto que se irritava só de vê-lo [...]" (2004, p.48).

É certo que o seu desempenho contribuiu demasiado para uma revisão e até renovação não só das letras nacionais, como também do comportamento de todos aqueles que se demonstravam mais sensíveis às transformações que vinham ocorrendo em virtude da sociedade capitalista que aqui tardiamente se solidificava. Contudo, valendo-se do conhecimento popular de que não devemos cutucar uma onça com vara curta, porque, inevitavelmente, terminamos com alguns bons arranhões, entendemos que no caso de Oswald de Andrade não foi muito diferente, mas, em vez de arranhões, nosso exímio autor acabou

\footnotetext{
${ }^{*}$ Ane Costa de Oliveira é licenciada em Letras pela UFRGS. Atualmente é aluna do mestrado em Literatura Brasileira do Programa de Pós-Graduação em Letras da UFRGS e professora de português titular da rede municipal de Sapucaia do Sul. anesbela@yahoocom.br
} 
amargando o isolamento, silêncio e esquecimento oriundos da incompreensão do seu poder criador - Jorge Amado o definira como mestre e quase ilha (AMADO apud HELENA, 1985, p.15). Paulo Prado também já predissera semelhante caracterização no prefácio à poesia Pau Brasil (1924): "O manifesto que Oswald de Andrade publica encontrará nos que lêem (essa ínfima minoria) escárnio, indignação e mais que tudo - incompreensão" (PRADO apud SCHWARTZ, 1983, p.153). Assim, sua obra permaneceu, infelizmente, durante um prolongado período, apenas na estante da crítica literária brasileira.

Resgatado, principalmente, pelo crítico Antonio Candido e por Haroldo de Campos, nas últimas décadas, Oswald de Andrade passou a ter sua voz ouvida e o seu valor devidamente reconhecido como um dos expoentes do Modernismo Brasileiro. Foi um dos principais idealizadores e organizadores da Semana de Arte Moderna, fundador, redator, colaborador e crítico de importantes jornais, revistas e periódicos, autor do Manifesto da Poesia Pau-Brasil (1924) e do Manifesto Antropófago (1928). Partidário, foi militante do Partido Comunista do qual se desligou em 1945 por se sentir, segundo Candido (2004, p.51), deixado de lado. Chegou ainda a se candidatar como deputado pelo Partido Trabalhista Nacional, mas também nesse não obteve o sucesso esperado.

Homem de atitude cosmopolita, ainda no começo da década de 20 , tem intensa vivência internacional, fruto das suas relações com renomados artistas estrangeiros como, por exemplo, Brancusi, Picasso, Cocteau, entre outros. Schwartz (1983, p.161) pergunta que sentido teria essa experiência internacionalista para a produção literária de Oswald de Andrade e, para tanto, responde que o caráter cosmopolita do referido autor criou um vínculo inalienável na relação vida-obra sendo, então, mais fácil entender que nesse binômio um termo é tão importante quanto o outro. No Prefácio Inútil, redigido como apresentação do primeiro volume de Um homem sem profissão - Memórias e confissões (1954), Candido destaca:

Um escritor que fez da vida romance e poesia, e fé do romance e da poesia um apêndice de
vida, publica as suas memórias. Vida ou romance? Ambos, certamente, pois em Oswald de
Andrade nunca estiveram separados, e a única maneira correta de entender a sua vida, a sua
obra e estas Memórias, é considerá-los deste modo. (CANDIDO apud SCHWARTZ, 1983,
p.161)

Assim, compreender como a criação poética decorrente da sua vida pessoal dá lugar a um texto como Memórias Sentimentais de João Miramar (1924), que se encontra harmonizado com uma dimensão mais global, torna-se uma interessante tarefa, visto que o próprio Oswald de Andrade chegou a se reconhecer como autor-personagem das peripécias miramarinas - "Meu nome é Miramar" (CAMPOS, s/d, p.13). 
Em Digressão Sentimental sobre Oswald de Andrade (2004), publicado primeiramente em 1970, Candido faz o balanço de outro ensaio de sua autoria - Estouro e Libertação (1945) - confessando que a sua tentativa de analisar o conjunto da obra de Oswald de Andrade talvez tenha o único mérito o fato de ter sido a mais longa apresentada até aquela ocasião. Naquele trabalho, o crítico de 25 anos ainda não havia alcançado suficiente amadurecimento para reconhecer que nosso entusiasmado gênio estava errado em anunciar que Marco Zero (1942) seria a sua obra máxima (cf. CANDIDO, 2004, p.35).

Passados alguns anos, podemos dizer que Candido admite ter se deixado impressionar por uma "espécie de fama antecipada" (2004, p.33) que fora em boa parte alimentada pelo próprio Oswald de Andrade e que havia gerado expectativa não só no jovem crítico, como nos demais colegas e público em geral. Ansiosamente, aguardava-se por aquela que deveria ser a grande obra de cunho assumidamente mais social de um autor por muitas vezes tão contundente. Infelizmente, Marco Zero não superou o impacto dos seus precedentes, decepcionando a todos aqueles que esperavam mais de Oswald de Andrade. Mas, respaldados na posterior percepção de Candido, perguntamos: por que a espera, se tudo o que depois “viesse viria por acréscimo”? (2004, p.38). O “par ímpar” (CANDIDO, 2004, p.52) Memórias Sentimentais de João Miramar (1924) e Serafim Ponte Grande (1933), assim como alguns outros excelentes e diversos trabalhos, já tinha confirmado a Oswald de Andrade o seu lugar em nossa literatura.

Ainda em Digressão Sentimental sobre Oswald de Andrade, Candido apresenta dois traços (devoração e mobilidade) que para ele são comuns às personalidades humanas e artísticas de Oswald de Andrade. A devoração ou a deglutição, muito mais do que a alegoria moderna ${ }^{1}$ central do Manifesto Antropófago, é o próprio jeito de ser oswaldiano. Sempre bastante curioso, Oswald de Andrade tinha sede, fome de mundo, de todo o mundo - as mais variadas formas eram por ele ingeridas para depois serem devolvidas num eloqüente arroto. É claro que durante a digestão ele absorvia o que lhe interessava, enriquecendo-se com isso. Candido até destaca a expressão do seu rosto como uma afirmação dessa intrínseca relação entre autor e obra: "os olhos arregalados e fixos, a boca aberta, um fácies imobilizado na absorção, que de repente se desfazia na fuzilada dos risos, trocadilhos e conceitos. Imaginemos que esta aparência simbolize a abertura sôfrega em relação ao mundo" (2004, p.49).

\footnotetext{
${ }^{1}$ Como veremos mais adiante, para Helena (1985, p.21), a metáfora do pau-brasil e da antropofagia são alegorias modernas que explicitam o início de uma nova perspectiva artística-social da modernidade brasileira.
} 
Em relação à mobilidade, talvez possamos apontar algumas características do comportamento do escritor citadas por Candido:

A mania de conhecer as pessoas e a insistência em ver as que conhecia; a rapidez com que enjoava de quem na véspera punha nas nuvens; a busca ingênua de contato com os estrangeiros de passagem; o convívio em tantos ambientes diversos; a familiaridade com argentários e políticos, manifestando um cândido arrivismo; mas também com motoristas e tipos da rua, vigaristas e caboclos, que o divertiam imensamente e ele ia armazenando. (2004, p.49)

Evidentemente, esses traços de devoração e de mobilidade se complementavam ou alargavam na mesma medida. Interessante é notá-los como uma forma de constante renovação, para evitar a estagnação que atrofia a essência da própria liberdade, ou seja, o próprio ser oswaldiano: as viagens, as mudanças de casas e de alianças, e a variação de contatos humanos são citados por Candido (2004, p.52) como manifestações de uma lei de sucessão vertiginosa e reconstituinte que foi seguida consciente ou inconscientemente por Oswald de Andrade.

Memórias Sentimentais de João Miramar ${ }^{2}$ é um bom exemplo dessa fusão autor e obra. Nesse romance, temos no protagonista traços da devoração e da mobilidade oswaldiana - quem conhece um pouco mais da vida de Oswald de Andrade logo reconhece a transposição literária das vivências pessoais do autor: João Miramar também gosta de viagens, de conhecer pessoas e lugares, de mergulhar no mundo. Dessa imersão, absorve o que lhe interessa como um casamento, diferentes amores, a sociedade numa empresa cinematográfica e a variedade de contatos humanos, por exemplo.

Refletindo sobre a análise feita por Haroldo de Campos em Estilística Miramarina (1967), entendemos ainda mais essa relação que nos propomos a melhor elucidar entre as impressões oswaldianas e o seu texto em questão. Ao definir a prosa miramarina como "cubofuturismo plástico-estilístico" (1967, p.87), Campos coloca que tal obra parece produto do impacto causado pelas descobertas de Oswald de Andrade nos museus europeus do início do século XX. Tais espaços encontravam-se recheados de legítimos exemplares cubistas e futuristas que apresentavam reconstruções da realidade feitas por artistas que já experimentavam uma nova sensibilidade poética - Picasso e Braque são alguns dos nomes dessas vertentes.

A partir das suas observações acerca do trabalho de Jakobson no qual esse crítico formalista russo concebe que o cubismo teria uma tendência metonímica, enquanto que o futurismo teria uma predileção metafórica (1967, p.88), Campos mostra como Memórias

\footnotetext{
${ }^{2}$ Neste trabalho, concentramo-nos na análise de Memórias Sentimentais de João Miramar, embora boa parte da crítica feita a essa obra sirva também como ponto de partida para a observação de Serafim Ponte Grande.
} 
Sentimentais de João Miramar realiza-se muito mais em um âmbito cubista no qual há uma orientação nitidamente metonímica.

\section{GARE DO INFINITO}

Papai estava doente na cama e vinha um carro e um homem e o carro ficava esperando no jardim.

Levaram-me para uma casa velha que fazia doces e nos mudamos para a sala do quintal onde tinha uma figueira na janela.

No desabar do jantar noturno a voz toda preta de mamãe ia me buscar para a reza do Anjo que carregou meu pai. (ANDRADE, s/d, p.45-46)

Ao escrever o capítulo acima descrito ou ao colocar, por exemplo, em um outro momento, que "no silêncio tique-taque da sala de jantar informei mamãe que não havia Deus porque Deus era a natureza" (ANDRADE, s/d, p.47), Oswald de Andrade trabalha uma linguagem que nos aproxima do universo infantil de Miramar. No primeiro exemplo, o carro provavelmente deveria ser uma ambulância, e o homem um médico ou um agente funerário que viera buscar o corpo de seu pai, já que "a voz toda preta de sua mãe", preta de luto ou de tristeza, e o "Anjo que carregou meu pai” passam a idéia da morte paterna. Já através do trecho "no silêncio tique-taque da sala de jantar", entendemos que o único som naquele ambiente era o do relógio.

A sensibilidade perspicaz do autor pode ser vislumbrada à medida que ele seleciona elementos da realidade para transformá-los, segundo Campos (1967, p.61), em dígitos que serão, por sua vez, recombinados pela sua força criativa em uma nova ordem. Em Miramar na Mira (1964), Campos também já ressaltara essa incrível percepção visual do mundo "Oswald de Andrade é um ser visual por excelência" (CAMPOS apud SCHWARTZ, 1983, p.170) - capaz de transfigurar objetos em texto poético. A imagem poética surge a partir de um olhar moderno que fotografa. Analisando outros trechos da obra - "um cão ladrou à porta barbuda em mangas de camisa" e "uma lanterna bicor mostrou os iluminados na entrada da parede" (ANDRADE, s/d, p.60), Campos destaca:

A violência das compressões e transnominações a que é submetida a linguagem, a ênfase que se dá aos detalhes (barbas, mangas de camisa, lanterna), as novas relações de contigüidade que se engendram no contexto e que o engendram fazem com que uma informação trivial (a descrição de um casal chegando a um hotel) se transforme, pelo aporte de originalidade, numa informação estética. (CAMPOS, 1967, p.91)

Entretanto, o estilo cubista miramarino se afasta um pouco da concepção proposta por Bense - para esse autor, um texto cubista é aquele cuja realização se refere "ao texto em si mesmo, como o seu próprio objeto estético, no sentido da realidade do mundo que lhe é 
privativo" (BENSE apud CAMPOS, 1967, p.89) -, pois, conforme as palavras de Campos, há nesse texto um cubismo histórico:

No caso da prosa miramarina de Oswald de Andrade, o estilo cubista, a operação combinatória
ou metonímica nele realizada, está do lado do cubismo histórico, é ainda residualmente icônica
em relação ao mundo exterior. Propõe, no fundo, através da crítica à figura e à maneira
habitual de representar o mundo das coisas, e mediante uma livre manipulação dos pretextos
sí́nicos daquela e destas, um novo realismo comensurado à civilização da velocidade e da
máquina, à civilização que incluiu o cinema como seu aporte mais característico no elenco das
artes. (CAMPOS, 1967, p.91)

É bom recordar que eram tempos de inovações que viriam a se consolidar como importantes meios de criação humana, como é o caso do cinema que também acabou por influenciar outras formas de produção artística. Assim, é compreensível a transfiguração da metonímia da linguagem cinematográfica em um recurso possível às linhas de um texto como o de Oswald de Andrade. Segundo Campos (1967, p.89), o cinema está presente no estilo oswaldiano. Ele, enquanto amante de qualquer novidade, viveu-o e dele retirou as condições necessárias para a composição da sua própria técnica de montagem. A descontinuidade cênica, a articulação de planos díspares que se cortam e interpenetram, o golpe à sintaxe tradicional, o uso de elipses, a alusão e o espaço em branco são recursos bastante utilizados pelo autor.

Um sentido semelhante ao cubismo histórico apontado por Campos pode ser apreendido em parte nas entrelinhas do estudo de Helena (1985), visto que tal autora crê que sempre esteve presente em Oswald de Andrade uma intenção de fazer romance social, mas essa se expressou em diferentes formas de mímesis: uma forma mais naturalista que tem a obra de arte como a representação direta da realidade, sendo contínua a ela e estando submetida a uma moral didatizante, e outra de cunho modernista que tem a obra como produtora de uma realidade sem nenhum compromisso didatizante (cf. HELENA, 1985, p.85). É neste ponto que Helena (1985, p.85) reconhece em Oswald de Andrade um veio fragmentário, mas também alegórico.

Buscando um sentido mais global no qual possamos inserir Memórias Sentimentais de João Miramar, ressaltamos que a alegoria é apresentada por Helena (1985, p.17) como alicerce principal da poética de Oswald de $\operatorname{Andrade}^{3}$ na medida em que essa pode se configurar como um elemento provocador de mudanças radicais na produção e na recepção artística. É através dela que se pode captar uma dialética de correspondências entre a obra e o

\footnotetext{
${ }^{3}$ Helena (1985, p.37) considera que as alegorias do pau-brasil e da antropofagia representam na obra de Oswald de Andrade uma relação histórica entre um passado pré-colonial ou próximo e um presente possível (a utopia da Pindorama) e questionador. No Manifesto Pau-Brasil (1924), o referido autor buscou a fusão da floresta com a escola enquanto que no Manifesto Antropófago (1928) ele evidenciou a deglutição crítica da escola pela floresta.
} 
social. Sabemos que o procedimento alegórico não é exclusivo da modernidade (na Idade Média e no Barroco ele já havia sido utilizado), contudo, ele se ajusta perfeitamente à proposta das vanguardas, compartilhada por Oswald de Andrade, de contestação dos padrões até então considerados como fundamentais para a arte ou para o Belo clássico como a autenticidade, a unicidade e o sacralizado (cf. HELENA, 1985, p.32).

Benjamim, em $O$ drama barroco alemão, foi quem melhor identificou o procedimento alegórico moderno, conforme mostra Helena (1985, p.28). Pela alegoria moderna temos acesso à experiência do choque que caracterizou a crise de um mundo burguês em que as relações sociais encontravam-se fragmentadas depois de terem sofrido o impacto da guerra, da industrialização, da automatização e da urbanização. Entendemos a partir desse, e também de outro trabalho benjaminiano, O Narrador (1983), que o homem moderno acabou por substituir a esfera da coletividade pela da individualidade. Essa substituição se configura como uma "individual e solitária aventura cercada dos choques do mundo urbano, na grande metrópole povoada de anônimos passantes" (HELENA, 1985, p.86) que pode ser apontada como a possível motivação que levou Oswald de Andrade a escolher escrever as memórias fragmentadas do seu protagonista: a memória é justamente o que nos individualiza.

Marcado por uma sensação de ruptura, o homem que desse corte nasce já não crê mais na fé ou na razão absoluta e por isso passa a buscar na arte novos caminhos que o ajudem a não sucumbir por completo - é o caso do escritor João Miramar que nos é introduzido por Machado Penumbra, autor do prefácio de Memórias Sentimentais de João Miramar, que pode ser visto como um manifesto a exemplo do Pau-Brasil e do Antropófago:

\footnotetext{
João Miramar abandona momentaneamente o periodismo para fazer a sua entrada de homem moderno na espinhosa carreira das letras. E apresenta-se como o produto improvisado e portanto imprevisto e quiçá chocante para muitos de uma época insofismável de transição. Como os tanks, os aviões de bombardeio sobre as cidades encolhidas de pavor, os gases asfixiantes e as terríveis minas, o seu estilo e a sua personalidade nasceram das clarinadas caóticas da guerra. Porque eu continuarei a chamar guerra a toda esta época embaralhada de inéditos valores e canglorosas ofensivas que nos legou o outro lado do Atlântico com as primeiras bombardas heróicas da tremenda conflagração européia. (ANDRADE, s/d, p.43)
}

Não podemos esquecer que toda a obra literária é mímesis e, portanto, configura-se como uma articulação entre o real e o imaginário na qual o mundo empírico não se esgota no ficcional. Compreendemos, assim, a possibilidade de "ficcionalização" do real e de "realização" do ficcional que um texto pode apresentar. No entanto, cabe lembrar que o autor sempre faz uma seleção das suas vivências empíricas e imaginárias no momento da sua escrita e as reestrutura a seu bel-prazer. Nem uma crítica sociológica ou psicologista podem negar esse intercâmbio entre obra e realidade. O que ocorre são diferentes gradações de perspectiva, 
podendo o autor ora ocultar a interrelação da obra com o imaginário, criando uma ilusão de reflexo (obra dita como mais realista), ora explicitar a descontinuidade em relação ao real - a linguagem produz a realidade (obra não-realista).

A descontinuidade (são capítulos curtos, cartas, bilhetes, prosas-poéticas, uma entrevista e até anúncio fúnebre que vêm à memória do protagonista sem apresentar ordem seqüencial) permite a fragmentação, o abandono da unidade e a pluralidade de significações serem as principais características diferenciais de Memórias sentimentais de João Miramar. É nas suas lacunas abertas e no seu aparente desconcerto que se concentra toda a sua força crítica podendo o leitor identificar, por exemplo, uma espécie de diálogo paródico com o Romantismo no capítulo seguinte:

\section{INDIFERENÇA}

Montmartre

E os moinhos do frio

As escadas atiram almas ao jazz de pernas nuas

Meus olhos vão buscando lembranças

Como gravatas achadas

Nostalgias brasileiras

São moscas na sopa de meus itinerários

São Paulo de bondes amarelos

E romantismos de árvores noctâmbulas

Os portos de meu país são bananas negras

Sob palmeiras

Os poetas de meu país são negros

Sob bananeiras

As bananeiras de meu país

São palmas calmas

Braços de abraços desterrados que assobiam

E saias engomadas

$\mathrm{O}$ ring das riquezas

Brutalidade jardim

Aclimatação

Rua de La Paix

Meus olhos vão buscando gravatas

Como lembranças achadas. (ANDRADE, s/d, p.61)

Oswald de Andrade evidencia o caráter econômico que assumiram as relações sociais burguesas. "O ring das riquezas" mencionado pelo escritor está de certa forma presente nas observações de Miramar acerca do casamento - "o casamento é um contrato indissolúvel" (ANDRADE, s/d, p.58) ou "separação precavida de bens" (ANDRADE, s/d, p.64) - ou na que ele faz sobre Rolah - "E Rolah trazia ao meu céu de cinema um destino invencível de letra de câmbio" (ANDRADE, s/d, p.54). Pelos neologismos criados pelo autor igualmente 
podemos perceber como a sua sátira irônica pode ser sutil e refinada: unindo as palavras ouro e urinol em um só termo "ourinóis" (ANDRADE, s/d, p.93), ele ridiculariza a burguesia que usa os dois.

Mas, conforme Campos (s/d, pp. 11-13), ${ }^{4}$ Oswald de Andrade também cria personagens como Machado Penumbra, Dr. Pôncio Pilatos da Glória, Dr. Mandarim Pedroso, o poeta Sr. Fíleas e Minão da Silva, agregado da fazenda de Miramar e "jovem orgulho mulatal" (ANDRADE, s/d, p.76) do Grêmio Bandeirantes, para criticar a sociedade pseudoerudita brasileira que sustenta um "beletrismo oratório-acadêmico" (CAMPOS, s/d, p.12) como um modo de marcar uma distinção superior. Esta última figura ainda é destacada como uma "sátira dentro da sátira" (CAMPOS, s/d, p.13).

Longe de pretendermos abarcar toda a complexidade de Oswald de Andrade, traçamos apenas uma breve revisão do que importantes estudiosos já disseram acerca da sua obra, em especial, Memórias Sentimentais de João Miramar, enfatizando como esse livro pode ser apontado como uma espécie de metonímia moderna oswaldiana, ou seja, como uma parte que bem expressa o espírito moderno desse escritor à medida que verificamos como autor e obra podem se diluir em traços comuns (devoração e mobilidade, por exemplo), mais evidente ficou nossa intenção de mostrar como o processo de criação do texto em questão se configura na ordem do mimético como uma articulação entre o real e o imaginário através da ficção.

É como se o 'homem do pau-brasil', com sua visão descontínua e fragmentária, se incorporasse aos personagens do Miramar e do Serafim (pois o procedimento nele se reitera) e a memória se constituísse como paródia das narrativas memorialísticas, do mesmo modo que se satiriza a sentimentalidade de um possível saudosismo. (1985, p.93)

Assim, compreendemos melhor as palavras de Helena, arriscando acrescentar ao "homem do pau-brasil", também o "homem da antropofagia", o "homem Oswald de Andrade". A partir do momento em que novos olhares foram lançados por áreas como a Psicanálise, a Lingüística e a Semiologia, notou-se que o sentido de um determinado elemento é um valor instituído pela relação que esse estabelece com os demais, conforme coloca Helena (1985, p.18). Tal constatação viabilizou ainda mais a linguagem como um meio possível de produção de realidades, de realidades ficcionais e de ficções reais. Atento a isso, Oswald de Andrade elaborou a sua obra Memórias Sentimentais de João Miramar com o cuidado de incluir nessa as inovações estéticas que fomentavam seu pensamento da época e que lhe permitiam captar a realidade brasileira de um ângulo mais incisivo, irônico, satírico ou até agressivo. 


\section{Referências}

ANDRADE, Oswald de. Memórias Sentimentais de João Miramar. Rio de Janeiro: Record/Altaya, s/d.

BENJAMIN, Walter. O Narrador: observações sobre a obra de Nikolai Leskow. In:

Textos escolhidos - Os pensadores. 2 ed. São Paulo: Abril Cultural, 1983. Trad. José Lino Grünnewald ... [et al.].

CAMPOS, Haroldo. Estilística miramarina. In: Memórias Sentimentais de João Miramar. Rio de Janeiro: Record/Altaya, s/d. p.5-33.

CAMPOS, Haroldo. Miramar na mira. In: Metalinguagem: ensaios de teoria e crítica literária. Petrópolis, Rio de Janeiro: Vozes, 1967. p.87-97.

CANDIDO Antonio. Digressão Sentimental sobre Oswald de Andrade. In: Vários Escritos. 4. ed. São Paulo, Rio de Janeiro: Duas Cidades, Ouro sobre Azul, 2004. p.33-66.

HELENA, Lúcia. Totens e tabus da Modernidade Brasileira: Símbolo e alegoria na obra de Oswald de Andrade. Rio de Janeiro: Tempo Brasileiro, 1985.

SCHWARTZ, Jorge. Convergências, Divergências: Oliverio \& Oswald. In: Vanguarda $e$ cosmopolitismo na década de 20: Oliverio Girondo e Oswald de Andrade. São Paulo: Perspectiva, 1983. p.153-206.

SCHWARTZ, Jorge. Vanguardas em confronto: Manifestos e Revistas. In: Vanguarda $e$ cosmopolitismo na década de 20: Oliverio Girondo e Oswald de Andrade. São Paulo: Perspectiva, 1983. p.45-73.

\footnotetext{
${ }^{4}$ Esta referência não está datada, pois o trabalho em questão (Miramar na mira, de Haroldo de Campos) foi publicado como ensaio introdutório de Memórias Sentimentais de João Miramar pela editora Record/Altaya.
} 